\title{
ОЦЕНИВАНИЕ КАЧЕСТВА ЭНТОМОКУЛЬТУРЫ ПРИ РЕАЛИЗАЦИИ ПРИРОДОПОДОБНЫХ ТЕХНОЛОГИЙ ДЛЯ ЕЕ ВЫРАЩИВАНИЯ
}

\author{
Пищанская Н.А., Бельченко В.М. \\ Инженерно-технологический институт «Биотехника» НААНУ \\ pishchanskay@gmail.com
}

\begin{abstract}
Adaptive technologies for growing entomocultures envisage the use of nature-friendly technologies and a set of equipment in order to cultivate entomocultures adapted to certain natural and climatic conditions of their use, which should ensure an increase in the efficiency of commercial forms of entomological plant protection products in agrocenoses. The criteria for assessing nature-like technologies and technical means ensure their optimization, which is carried out according to one or several indicators simultaneously. To analyze the quality of insects, general indicators are considered that assess the degree of adaptability of entomocultures to artificial breeding conditions, and target ones that assess the degree of effectiveness of entomocultures when using it.
\end{abstract}

Key words: nature-like technologies, quality of entomocultures, search activity, migration activity, predatory activity.

\section{Введение}

Одним из основных критериев оценки внедрения адаптивных технологий выступает качество насекомых. Для оценки качества энтомологической продукции показатели делятся на общие и целевые. При разведении маточной энтомокультуры контроль общих показателей качества является обязательным. При массовом производстве энтомопродукции контроль целевых показателей качества осуществляют в соответствии с действующей нормативной документацией, а при необходимости контролируют и общие показатели качества [1].

Общие показатели оценивают степень приспособленности энтомокультуры к искусственным условиям разведения. Целевые показатели оценивают степень эффективности насекомых при их применении. Внедрение природоподобных (адаптивных) технологий оказывает влияние на целевые показатели.

\section{Материалы и методы}

Качество энтомофагов (хищники, массовая энтомокультура) определяется тремя основными целевыми показателями: поисковая активность $\beta$, миграционная активность $\delta$, хищническая активность $\varepsilon$. Исследования авторов, в том числе ИТИ «Биотехника», доказали влияние составляющих адаптивных технологий (заданный температурный и влажностный режимы, имитация день-ночь, движение воздуха и др.) на качество насекомых.

$$
\beta=\frac{\sum N_{i}^{\text {пар }}}{\sum N}, \delta=\frac{\sum N_{i}^{\text {дош }}}{\sum N}, \varepsilon=\frac{\sum N_{i}^{\text {пар }}}{\sum N}
$$

где $\sum N-$ общее количество энтомокультур; $\sum N_{i}^{\text {пар }}-$ количество

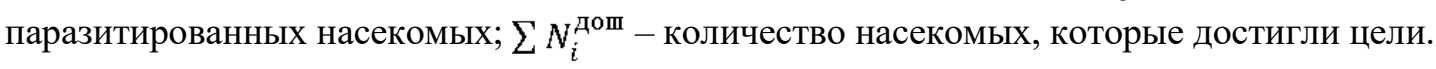

Проведены экспериментальные исследования на примере выращивания зерновой моли с применением принудительной организации движения воздуха с оптимальными параметрами (температура, относительная влажность, скорость) через равномерно установленные по объему воздуховоды [2]. Это обеспечило конвективный отвод тепла и максимальное получение энтомопродукции. 
Решающее значение для обеспечения эффективного подавления популяции вредителей имеет качество используемого биоагента, которое зависит от исходной маточной культуры, от строгого соблюдения необходимого климатического режима при разведении, а также качества корма [3]. Соблюдение стандартных показателей качества биоагента позволяет поддерживать производство качественного биоматериала, следовательно его биологическую и экономическую эффективность. Для сохранения качественных показателей наработанного биоматериала необходимо также проводить регулярное обновление популяции биоагентов и проведение пассажа через природного хозяина.

\section{Результаты и обсуждение}

Была проведена оценка адаптивности трихограммы в различных температурных условиях. Для исследования было выбрано два целевых показателя, отражающие возможность нахождения самкой трихограммы яиц природных хозяев.

Наиболее широкий диапазон благоприятных температур (при которых поисковая активность самок превышает 0,5) и самую высокую поисковую активность $(0,75)$ проявляла естественная (природная) популяция трихограммы (рис. 1).

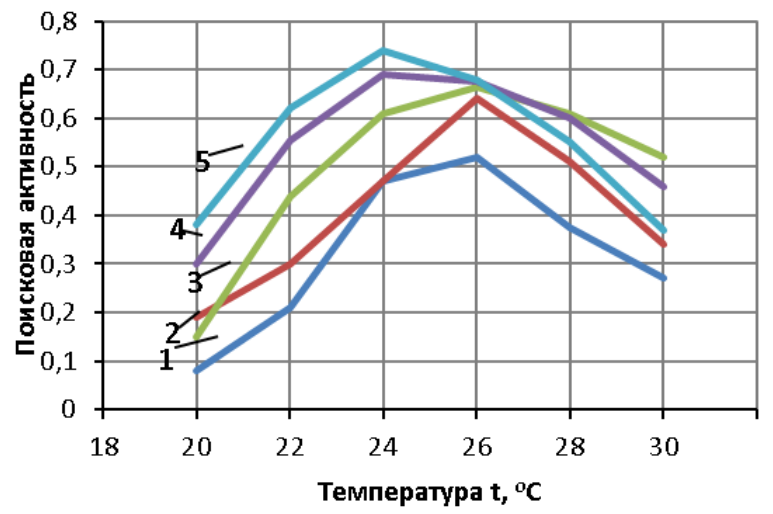

Рисунок 1 -Поисковая активность трихограммы при различных температурах $(1-$ рабочая культура E1110O, 2 - популяция по методике Rezniketall, 2010, 3 - популяция по экспериментальной методике 1983, 4 - популяция по экспериментальной методике 2020, 5 - природная популяция)

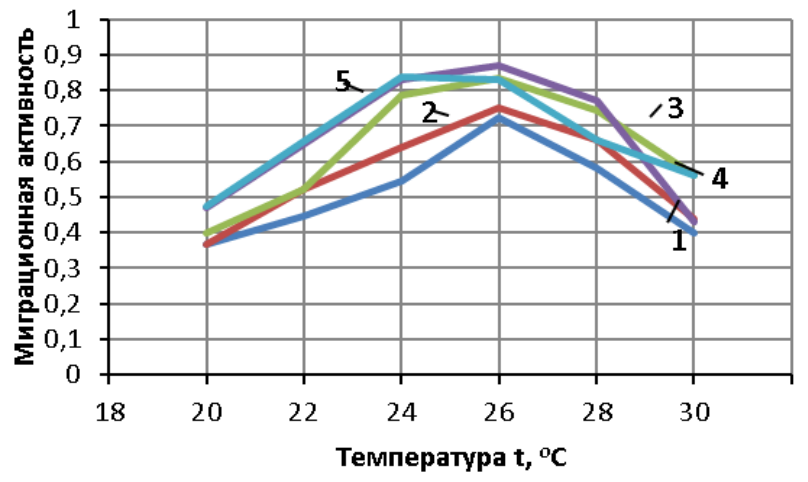

Рисунок 2- Миграционная активность трихограммы при различных температурах (1 рабочая культура E1110O, 2 - популяция по методике Rezniketall, 2010, 3 - популяция по экспериментальной методике 1983, 4 - популяция по экспериментальной методике 2020, 5 - природная популяция) 
Максимально приближена к естественной популяции - трихограмма, которую разводили по новой методике $(0,69)$. По методикам других авторов, на высоком уровне были результаты трихограммы в 3-м варианте.

Трихограмма во 2-м варианте имела такую же максимальную поисковую активность, однако значительно меньше диапазон благоприятных температур. Показатели рабочей культуры можно назвать удовлетворительными лишь при температуре $26^{\circ} \mathrm{C}$.

Аналогичными были результаты оценки миграционной способности трихограммы (рис. 2).

Показатели качества трихограммы определялись 3-4 раза за один период разведения, в том числе определение поисковой способности, с помощью устройства ОКИ-1 (рис. 3).

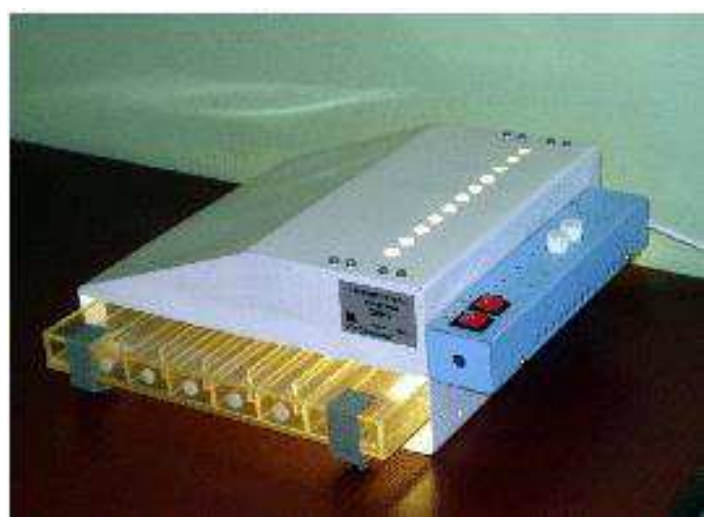

Рисунок 3 - Устройство определения качества интегральный ОКИ-1

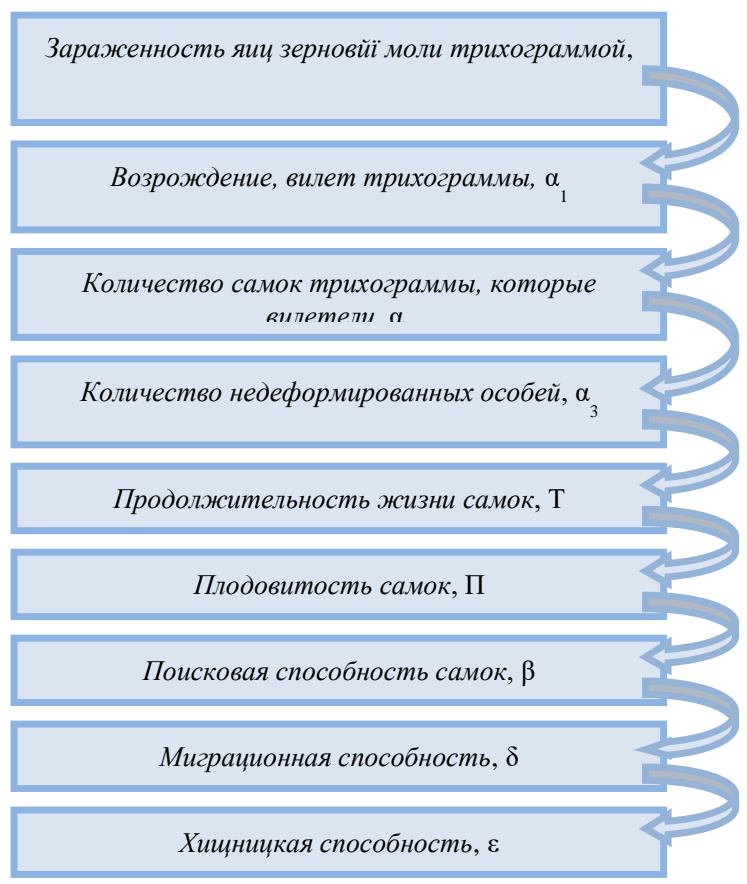

Рисунок 4 - Блок-схема методики текущего экспресс-анализа эффективности адаптивных технологий выращивания энтомокультур

Устройство ОКИ-1 состоит из камеры со светильниками (3 шт), блока питания (1 шт) и термостата (1 шт). В свою очередь камера состоит из двух отсеков: для запуска трихограммы, размещение почерневших яиц зерновой моли перед самым вылетом яйцееда и для размещения карточек с яйцами живителя. Отсеки соединены между собой каналом, длина которого 3 м, что соответствует радиусу эффективного действия трихограммы в полевых условиях.

Оценка показателя поисковой способности трихограммы осуществлялась по количеству паразитированных яиц зерновой моли или природного живителя при заданном гигротермическом режиме (рис. 4). 
Для оценки поисковой способности по количеству (3-5 г) яиц, паразитированных трихограммой, отбирались три пробы по 0,5 г, распределялись в пробирки длиной 5-10 см и диаметром 8-10 мм, плотно закрывались, и выдерживались до начала лета при температуре $25^{\circ} \mathrm{C}$.

\section{Выводы}

1. Результаты исследования показали, что особи природной популяции трихограммы имеют высокие показатели жизнеспособности а также адаптивности к различным температурным условиям.

2. Использование экспериментальной методики разведения трихограммы при переменных температурах позволило приблизиться к показателям природных популяций.

3. Методики других авторов имели значительный эффект, однако было видно, что такие режимы не являются оптимальными для данной культуры, а соответственно методики требуют корректировки для каждой локальной популяции отдельно.

\section{Библиография}

1. Крутякова В. І., Бельченко В. М., Піщанська Н. О. Аналіз критеріїв оцінки адаптивних технологій. Біологічний метод захисту рослин: досягнення $і$ перспективи: матеріали Міжнар.наук.-практ. конф. 2018: С. 164-172.

2. Бельченко В. М., Піщанська Н. О. Оптимизация схемы подготовки воздуха для технологических процессов энтомологических производств. Інформ. бюл. СПРС МОББ. 2016, 49: C.35-40.

3. Krutyakova, V., Bulgakov, V., Adamovics, A., Pishchanska, N. Selection of optimal dimensions of air humidification section in microclimate preparation system for growing ofentomophages. 18-th International Scientific Conference "Engineering for rural development", Proceedings. 2019, 18: P. 1533-1538. 